\title{
Development of Effective Extracurricular Construction Technology Educa- tion Programs for University and Industry Collaborations
}

\section{Dr. Dan Koo, Indiana University Purdue University, Indianapolis}

Dr. Koo is an assistant professor in the department of engineering and technology at Indiana University and Purdue University Indianapolis (IUPUI). Dr. Koo is also a registered PE. Dr. Koo's research and professional activities are primarily focused on heavy civil infrastructure system, underground infrastructure system management and development, trenchless engineering, and sustainability. Dr. Koo received a Ph. D in Civil and Environmental Engineering and MS in Construction Management at Arizona State University in 2007 and 2003 respectively; and a BE degree in Civil Engineering from South Korea in 1999.

\section{Mr. J. William White AIA, Indiana University Purdue University, Indianapolis}

J. William White AIA is a lecturer with the Construction Engineering Management Technology program within the Purdue School of Engineering and Technology in Indianapolis. He is a registered architect who has more than 23 years of varied construction industry experience. Mr. White has undergraduate degrees from Indiana University and Ball State University and a masters degree from Purdue University Indianapolis. He is an active member of the American Institute of Architects and the Construction Specifications Institute. His professional interests include great architecture and all things related to construction innovation.

\section{Mr. Veto Matthew Ray, Indiana University Purdue University, Indianapolis}

Mr. Matt Ray is a lecturer for the Construction Engineering Management Technology Program offered through the Purdue School of Engineering and Technology at Indiana University Purdue University Indianapolis. He currently provides instruction for Soils and Foundations, Construction Cost and Bidding, Construction Project Cost and Production Control as well as managing the Certificate of Training in Asset Management. He is a graduate of Purdue School of Engineering and Technology receiving degrees in Construction Technology, Architectural Technology, and a Masters in Facility Management. His field experience includes residential construction and light commercial. He has been an architectural designer as well as a superintendent for single and multi-family construction projects. Mr. Ray worked as an engineering and design manager in the Building Component Manufacturing Industry for over fifteen years. 


\title{
Development of Effective Extracurricular Construction Technology Education Programs for University and Industry Collaborations
}

\begin{abstract}
Collegiate level construction engineering and management education has been significantly growing in recent decades as the construction industry keeps increasing the demand for qualified entry level employees who receive college level construction education. The construction industry aims to hire ready-to-work students with a strong fundamental construction knowledge and practical skill set including internship experience and extracurricular programs. The fundamental construction knowledge curriculum is well drafted in most construction programs, but the practical skill set is not sufficient. Therefore, many construction programs now require several credits of official internship as a part of the program requirements. However, practical implementation of extracurricular programs has not been effectively structured in many construction programs mainly due to lack of university-industry collaboration, missing guidance of best practice, and insufficient level of student interest.

Several attempts have been made to develop effective extracurricular construction technology education programs. For example, a "living lab" is a practical concept which utilizes the local community as a real infrastructure development opportunity. Another example is a "new product review” process which provides students an opportunity to learn technical knowledge by providing a real engineering professional service to a local municipality. The authors present key issues identified from experience developing the extracurricular programs in our construction program and discuss impact factors on improving student readiness through the extracurricular programs.
\end{abstract}

\subsection{Introduction}

Some typical extracurricular activities, such as student organizations, volunteering organizations, sports teams, and academic clubs exist at most universities. However, extracurricular activities and programs closely associated with educational purposes have not been factored as core curricular structure in most collegiate level construction engineering and management programs in the United States. The Construction Engineering Management Technology (CEMT) program at Indiana University Purdue University Indianapolis (IUPUI) attempted several types of extracurricular programs for both undergraduate and graduate students in order to achieve several objectives including 1) improving practical skills for industry readiness, 2) improving professionalism, and 3) promoting strong team working skills.

Industry and university collaboration for construction engineering education was emphasized by many previous studies. The practice of construction engineering and management increasingly demanded construction professionals who are capable of solving many challenges both technical and social within a team environment ${ }^{1}$. However, there are many barriers to establishing effective university and industry collaborative partnerships. Several barrier factors were 
identified by Bruneel et al. ${ }^{2}$. The authors summarized some major factors including insufficient collaboration experience, limited breadth of interaction channels, uncertainty in project success, and ownership of data including intellectual property. Private industry management considered that assessment of evaluation of university and industry collaboration is the most difficult challenge ${ }^{3}$. Thus it has been a challenging task to establish an effective extracurricular project working together with industry. The CEMT program at IUPUI has created several opportunities in which students can assume vital roles in real world projects.

Two noteworthy attempts are noted in this paper. Both the living lab in a local community and the new product review process were developed and implemented by the CEMT program. Living lab is a practical concept to utilize a local community to serve as a real infrastructure development testing bed.

This paper describes our efforts to develop and implement the two extracurricular projects. The authors present key issues identified from their experience developing the extracurricular programs in the construction engineering management program and discuss factors for improving student readiness through extracurricular programs.

\subsection{Living Lab Development in a Local Community}

Living lab is a community project concept which utilizes a real-world setting for research to identify problems, introduce new technologies, and improve infrastructure services. Students involved in the living lab process assist in the development of infrastructure system rehabilitation and renewal to achieve sustainable living conditions. A team for the living lab project consists of many diversified and interdisciplinary members/partners, including undergraduate and graduate students, faculty, community leaders, utility owners, contractors, and technology providers. A local neighborhood selected for the living lab development is located close to the IUPUI campus in downtown Indianapolis as shown in Figure 1. The living lab area has experienced significant socio-economic decline and its underground infrastructure system is in dire need of rehabilitation and replacement. This living lab project was named as the Riverside Watershed Environmental Living Lab for Sustainability (RWELLS). The boundary of the Riverside community is shown in Figure 1.

The goals and objectives of the RWELLS team are to:

1) Engage residents in the community informing by them about the importance of water conservation.

2) Introduce smart water practices using real-time data and measurement to provide accurate estimates documenting treated water leakage in the community.

3) Refine the approach to such new technologies in a real-world setting with university and industry partners so that solutions can be implemented and eventually exported to other communities.

4) Provide leadership in the state by supporting student research that can be used by smaller communities who can adopt the best practices developed in this living lab. 


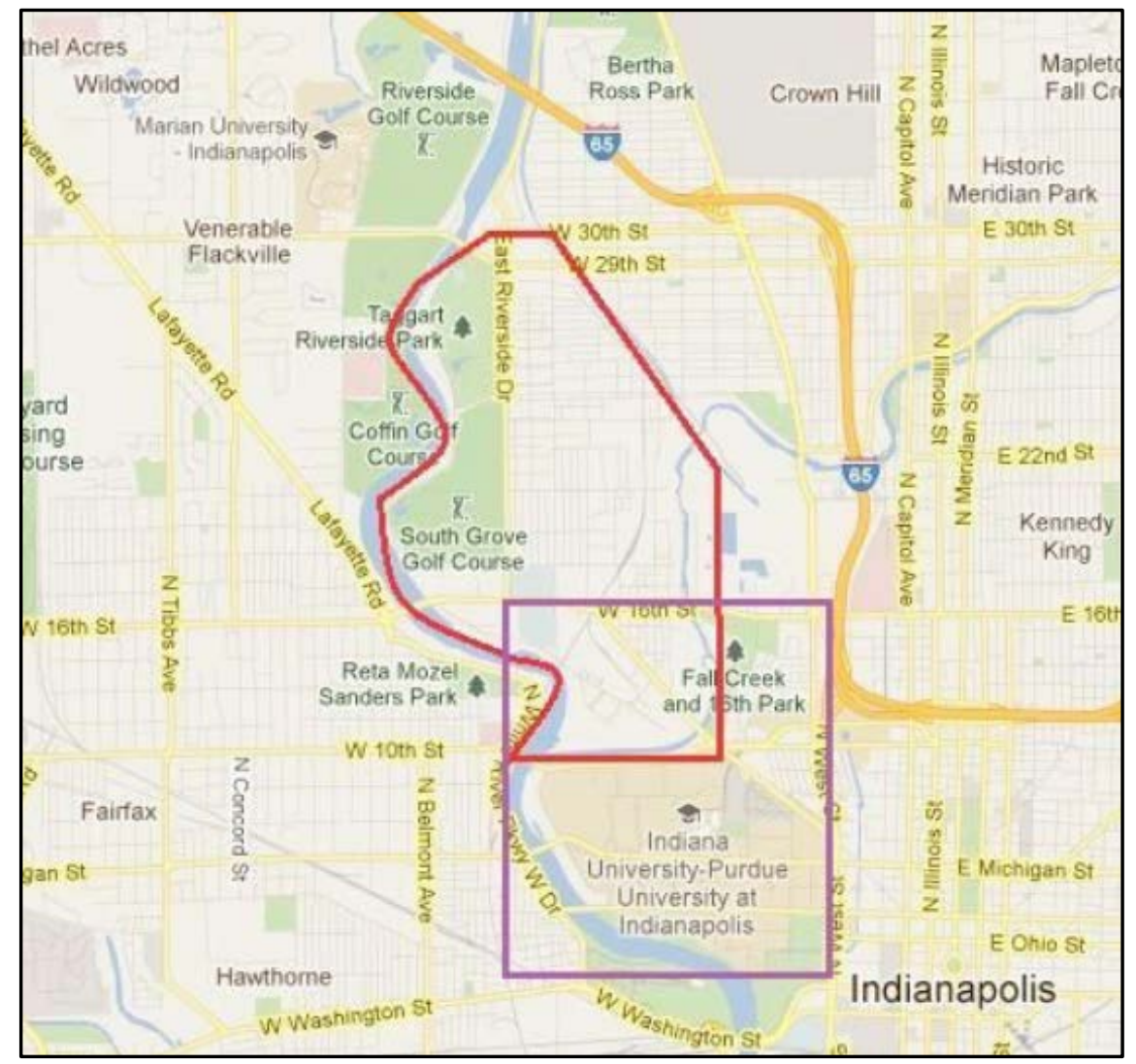

Figure 1. Location and Boundaries between Riverside and IUPUI

The main theme of RWELLS focuses on underground infrastructure assessment, development of new solutions and promotion of entrepreneurship opportunities within the Riverside community. A student team consists of 4-6 students with a faculty advisor working with other industry and community collaborators to conduct various study topics such as:

1) Working with utility owners conducting asset inventory, inspection, and assessment for underground infrastructure.

2) Developing a framework of an asset management program for RWELLS.

3) Working with GIS specialists and generating underground infrastructure maps as shown in Figure 2.

4) Working with community leaders to identify potential entrepreneurship and business opportunities. The student team also conducts demographic and socio-economic studies.

5) Conducting a review of technologies that can be implemented in RWELLS. 


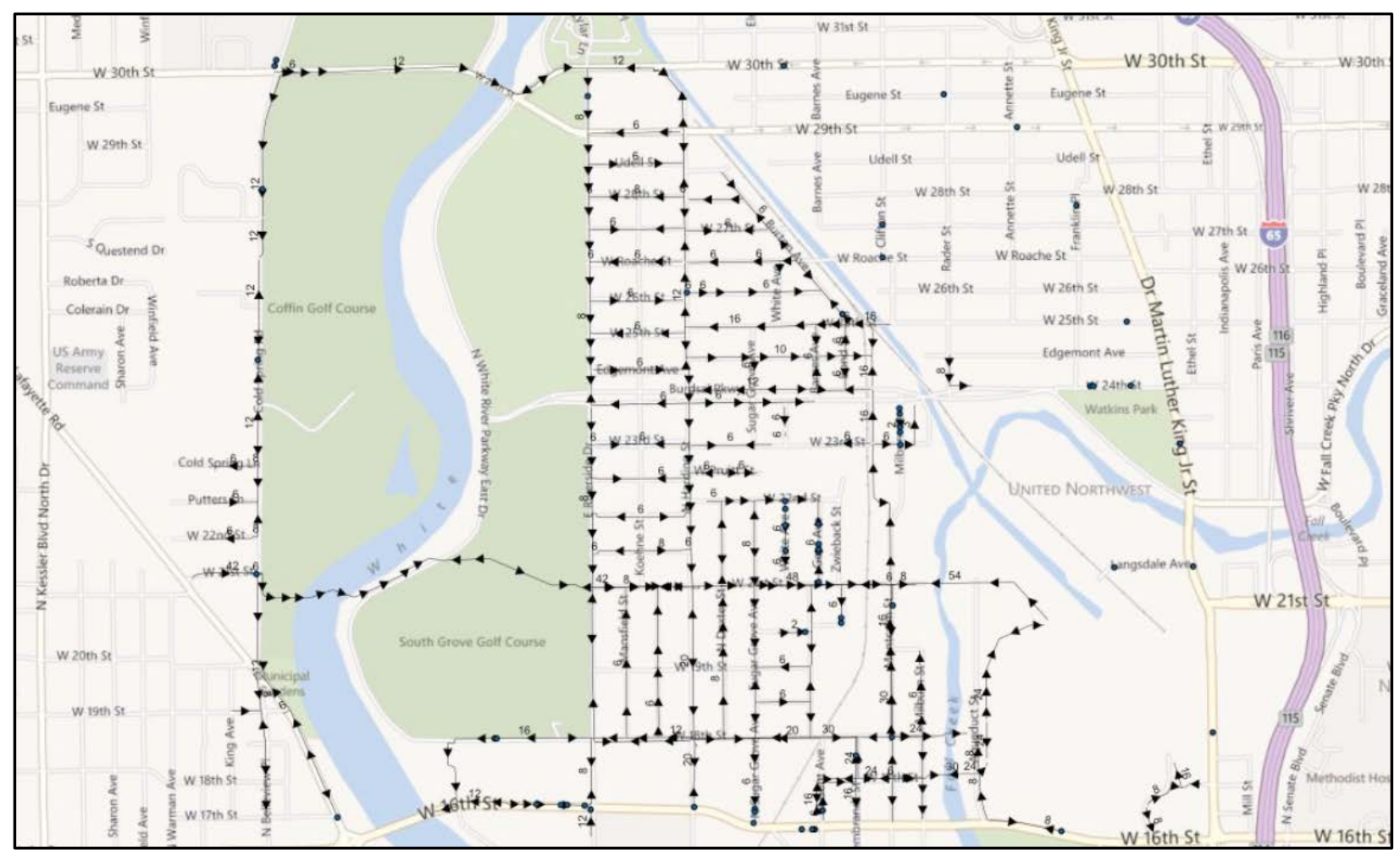

Figure 2. Water Mains and Flow Directions in Riverside Community Area

The student team served as a central hub of the RWELLS project. Several positive educational outcomes from this extracurricular program were achieved. Team work was emphasized as students had to lead and coordinate the project with other widely diversified team members. Technical challenges were encountered as the student team investigated the current condition and asset inventory of the community through data collection from the local water utility. They performed professional services including reviewing new technologies for evaluation and potential implementation in the RWELLS area. The student team also learned how to reconcile the challenges of working within a multi-disciplinary working environment as it attempted to resolve technical problems for the community, all the while remaining in-budget and sensitive to the socio-economic needs of the community. RWELLS demonstrated that a local community can serve as a living lab to establish an effective extracurricular project. The project provided a practical student experience of professional services.

\subsection{New Product Review (NPR) Project}

The CEMT program partnered with the City of Indianapolis Department of Public Works (DPW) to review new products and technologies that exhibit potential fulfillment of the city's infrastructure needs between 2009 and 2011. Prior to the NPR project with the CEMT program, the DPW hired professional engineers and consultants to review new products applications to support the DPW approval process. The basic concept of the NPR is collaborative and mutually 
benefits the three main parties - the new product representative who provides detailed information of new products, the student team who provides technical in depth review, and the government entity (DPW) who determines the approval of the product.

A total of 16 NPR projects were completed. Each NPR project was administered as an independent project. A NPR project begins with a formal service agreement between a product representative and IUPUI at a cost of \$5,000 per each agreement. Students involved in the NPR projects are compensated hourly to ensure accountability of their involvement. A student team consists of a team director and mix of several undergraduate and graduate students. They are responsible for collecting and analyzing product data and preparing a formal technical report. Students then make a final presentation to the DPW with a formal technical report. The final decision as to whether to adopt the product is then made by the DPW.

The NPR process generally consists of eight steps as follows ${ }^{4}$ :

Step 1: A product representative contacts the DPW or the CEMT program at IUPUI.

Step 2: The product representative provides preliminary information prior to acceptance of the product review.

Step 3: A contract is then executed between the product representative and the university.

Step 4: An NPR team schedules a product technical presentation by a product representative to the DPW.

Step 5: The NPR team commences researching the product by considering the utilizing sources including but not limited to:

- Technical presentation materials as supplied by the product representative

- Product description, technical data, test data, check lists, etc.

- Applicable standards and manuals (ASTM, AWWA, ASCE, NSF, ANSI, etc.)

- Example specifications

- Case studies

- List of previous projects and appropriate reference information

Step 6: The NPR team conducts a technical review and writes a report with conclusions within 30 days of completion of the technical presentation.

Step 7: The NPR submits a technical report to the DPW for further consideration.

Step 8: Reviewers in the DPW issues a letter of recommendation which either accepts or denies the product.

Because the DPW managed the city's public works including water and sewer systems, most new product review applications came from underground infrastructure system suppliers. NPR applications include for example, 1) new pipe materials, 2) storm water quality units, 3) new coating materials for existing manhole rehabilitation, 4) lining rehabilitation materials, and 5) pipe rehabilitation technologies. 
Since an NPR process requires a significant commitment that requires extensive study and research work, it is very important to select only committed and highly qualified students to form a student team. To assist in identifying these students, a pre-qualification process was developed.

The student pre-qualification process begins with a job announcement. The student recruitment process is similar to an actual hiring process in which a prospective student must submit a resume. A team director then reviews the resume and conducts interviews for a selection. Figure 3 demonstrates the NPR process and work flow diagram. A senior graduate student leads other students and plans for the reviewing process with the students.

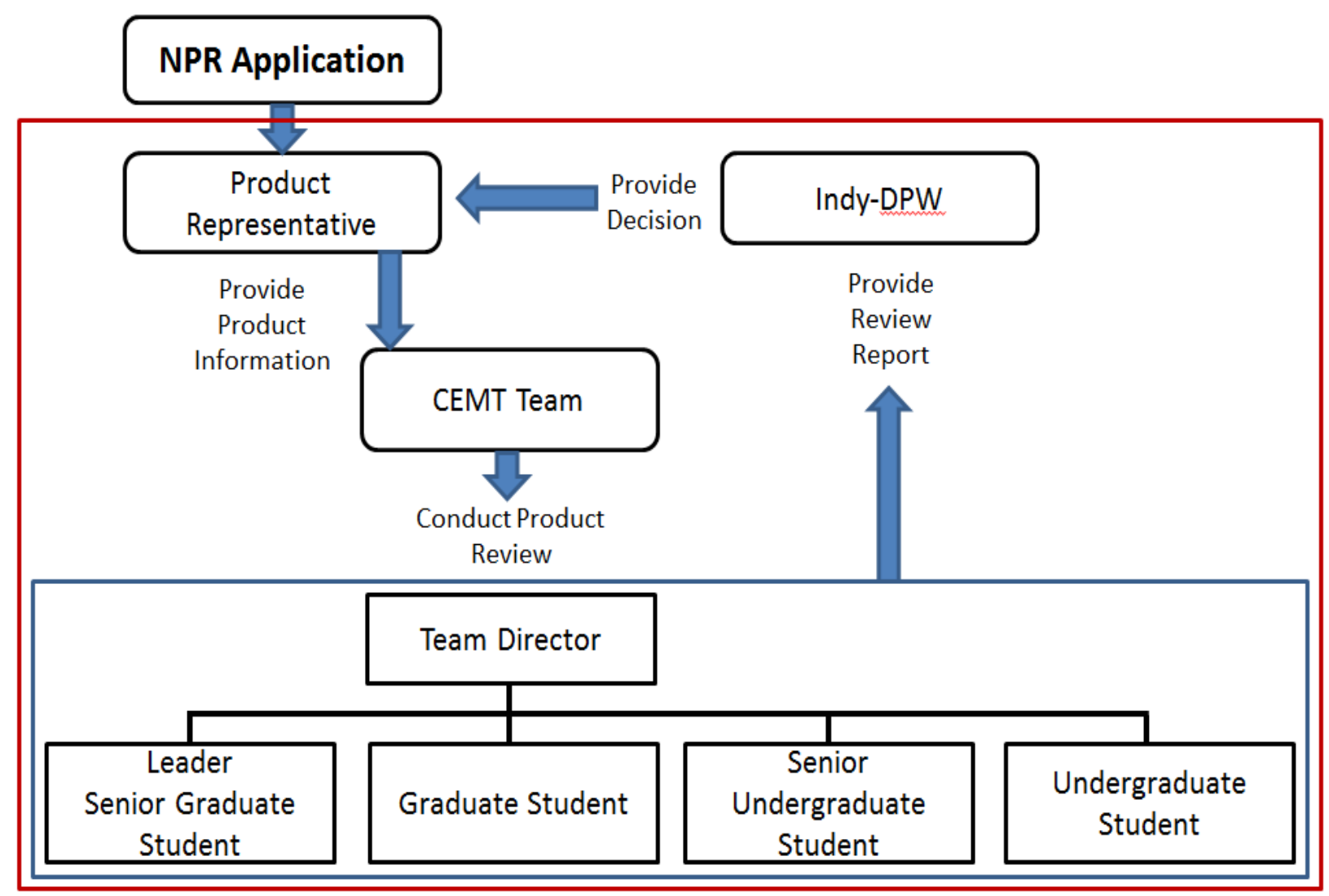

Figure 3. NPR Process Framework and Work Flow Diagram

All students in the team are expected to work together. A goal of this extracurricular program is to apply the principles and practices of construction engineering and management as taught in the class to real world professional service situations. As similar to organizing a professional engineering project team in a real world, a team director and leader will provide technical guidance, training, and education to help students conduct the review process. A team director is responsible for quality assurance and control of the final report and presentation. Undergraduate team members then follow the team director and leader's guidance and supervision to complete their assignments. 
The NPR product established several objectives in terms of educational benefits to the students. The NPR project objectives include:

- Acquiring professional experience while working with the DPW and a product representative

- Improving technical research capability

- Learning professional engineering process

- Understanding informative materials including standards and manuals, testing results, and reports

- Improving technical writing capability

- Improving technical presentation skills

- Improving team workmanship and collaboration

- Gaining job interview and resume building skills

The most significant benefit of the NPR project is to develop an effective collaborative relationship between industry, owners, and the university through a real world project. Students master the technical aspects and applications while completing various tasks. The concept of the NPR program is a valuable example that can be used by other construction programs as a framework to engage their own areas of expertise and specialties in the creation of extracurricular activities. Potential collaboration among other universities, industry partners, and municipalities is entirely possible and may have a chance to expand the NPR network.

\subsection{Effectiveness of the Programs}

Measuring the effectiveness of these programs at the student level is challenging as data are difficult to retrieve. Potential metric targets could include job placement rates upon graduation and improved academic performance in specific outcomes (e.g., team work, technical problem solving, and global issue awareness). An indirect measure of effectiveness of these two extracurricular programs could be the amount of industry exposure students enjoyed which far exceeds any typical classroom experience. One should consider the number of students and organizations involved. The RWELL program team was initiated in 2011 by three main entities including Riverside Civic League, IUPUI, and the Buried Asset Management Institute International (BAMI-I). Several technology providers and infrastructure owners participated as a part of the RWELL team and generated positive outcomes such as workshops, presentations, and an asset inventory study using GIS. The total number of organizations and companies involved in the RWELLS exceeded nine. The number of student involvement varies depending on student availability and work amount. The average number of students involved on any specific task was been between 3 and 4 .

The NPR program received over $\$ 53,000$ from 16 external contracts in a two year period between 2009 and 2011. A total of ten companies asked to review their products. The average number of students involved on each NPR contract was four to five undergraduate students and one or two graduate students. 
It was difficult to estimate an accurate number of available students per semester for the extracurricular programs. Thus, student benefits are more qualitative than quantitative. In speaking with the participating students, the following program benefits were mentioned:

- Public exposure for the CEMT program

- Obtained collaboration experience in working with the local community and government

- Research and learning experience through real-world cases

- Improved team work and leadership skills

\subsection{Key Issues for Developing Extracurricular Programs}

Enhancing extracurricular programs in real-world applications through construction engineering and management programs require cohesive collaboration with industry, community, and owners. However, there are several key issues that are hampering this effort.

The first issue is conflicting goals between industry partners and student education. One main difference is that research at the university level tends to be more academic oriented, while research in industry is more commercially based ${ }^{5}$. For example, the university's approach could be spurred by the desire to help people and create a learning environment, while industry may not be as interested if the potential for making money is not sufficient. Successful collaboration between the two can bridge these differences and make both of them a reality. Collaboration involves both parties teaching each other what is necessary to understand their side of the deal, and what is necessary to keep the partnership running for the long term.

The second issue is to maintain a constant interest level from students. An extracurricular relationship can easily fall apart if the students do not maintain close contact. Having the right industry connections in place to foster the relationship and keep the ever-changing crop of students working towards the goal can be challenging. Industry changes too, especially if a company is involved with multiple industries and projects, it can be difficult to stay focused on one thing, especially with the amount of turnover on the university side. Having a consistent, knowledgeable industry partner can prove to be very important. Edmondson et al. ${ }^{6}$ also discovered that one of the main elements of a successful collaboration is to "keep the ship steady," and that a stable environment is key for long-term strategic partnerships to thrive. Rewards and compensation for students' hard work go along with this, because students will not be as motivated to keep participating if they don't feel they are benefiting from the relationship. Obvious rewards include monetary compensation, in the form of a regular paycheck or stipend. Students also can be compensated with experience, which is becoming just as valuable. If working on such a project can increase career possibilities in partnering organizations or in industry in general, it is a positive outcome.

The third issue is finding appropriate topics for the program. Some topics can be found through problem recognition. Problem recognition is perhaps the most important factor in determining the basis for which the relationship is founded. The key to recognizing a problem is to define it in terms of both the university and industry. As with motivation in creating the partnership, one party may be more affected by a specific problem than the other, creating further conflicts of interest. Having a mutual decision making process should be established in order to ensure the success in the short and long term of the partnership. 
The fourth issue is establishing a long-term business plan between industry and the university. Perkman and Salter ${ }^{7}$ used two dimensions to describe the relationship between industry and universities, the first of which is the timeframe. The relationship can be short or long-term in nature. Regardless, a long-term plan should be developed for how to handle the relationship. Even short-term projects and relationships can be revisited or built upon with proper planning ahead of time. The second dimension is the degree to which the results of the partnership are disclosed. The overall point of Perkman and Salters ${ }^{6}$ research was to show that simply giving more thought and attention to the structure of the industry-university relationship structure can contribute to better results from the collaboration. For the success of current programs, as well as future programs, a partnership should be set up like a business, in which a plan is developed to explain in detail what both partners hope to accomplish as well as what they will contribute. Knowing what the goals are not only at the academic level, but for industry participants as well is key to a successful partnership. After establishing the nature of the relationship, the rest will fall into place much easier, and the chances for a successful extracurricular collaboration will greatly increase.

The fifth issue is establishing a proper plan for compensating faculty time and effort. Technical guidance to students and preparing professional reviews need experienced faculty's involvement. External funding source for the two extracurricular programs in this paper was not always sufficient to fully compensate faculty time and effort. Thus, a properly designed compensation plan to maintain continuous motivation and interest level should be implemented as the extracurricular activities and number of student involvement grow.

\subsection{Conclusions}

A successful extracurricular program where industry and academia join together has several key attributes. Discussing two existing programs can help display what is important in an extracurricular program. The main benefits of the CEMT extracurricular program include student improving their practical skills and knowledge, professionalism with commitment, and team work and leadership.

This paper briefly described the RWELLS and NPR programs' structure and benefits. Several key challenges were identified as follows:

- Conflicting goals between industry partners and student educations

- Maintaining a constant interest level from students

- Finding appropriate topics for the program

- Establishing a long-term business plan between industry and university

- Establishing a faculty time and effort compensation plan

The most fundamental aspect of the extracurricular program is that industry and university must collaborate effectively and seek mutual benefits from the students' involvement and services. The above issues have to be factored in when a new program is designed. 


\section{Bibliography}

1. Tener, R. (1996). ”Industry-University Partnerships for Construction Engineering Education.” J. Prof. Issues Eng. Educ. Pract., Vol. 122, Issue 4, 156-162.

2. Bruneel, J., D’Este, P. and Salter, A. (2010), “Investigating the factors that diminish the barriers to universityindustry collaboration. Research Policy”, 39, 858-868.

3. Perkmann, M., Neely, A., and Walsh, K. (2011). "How should firms evaluate success in university-industry alliances? A performance measurement system”, Vol. 41, Issue 2, pages 202-216.

4. Green, C., Vargas-Lamanna, O.L, Hashemi, B, and Iseley, D. T (2010), "An Innovative New Product Review Process for Moving Trenchless Technology into the User Community”, Proceeding for Nodig 2010, North American Society of Trenchless Technology (NASTT), Chicago, Illinois, May 2-7 2010.

5. Iqbal, Abeda Muhammad, Khan, Adnan Shahid, Iqbal, Saima, Senin, Aslan Amat. (2011), "Designing of Success Criteria-based Evaluation Model for Assessing the Research Collaboration between University and Industry”, International Journal of Business Research and Management. Vol 2, Issue 2.

6. Edmondson, Gail, Valigra, Lori, Kenward, Michael, Hidson, Richard L., Belfield, Haydn, Koekoek, Peter. (2012), “Making Industry-University Partnerships Work”, Science Business Innovation Board.

7. Perkmann, M. and Salter, A. (2012). "How to Create Productive Partnerships with Universities", MIT Sloan Management Review. 